\title{
CD117 expression is a predictive marker for poor prognosis in patients with non-small cell lung cancer
}

\author{
TOMOHIKO SAKABE ${ }^{1,2}$, JUNYA AZUMI ${ }^{1}$, TOMOHIRO HARUKI ${ }^{3}$, \\ YOSHIHISA UMEKITA ${ }^{2}$, HIROSHIGE NAKAMURA ${ }^{3}$ and GOSHI SHIOTA ${ }^{1}$
}

\author{
${ }^{1}$ Division of Molecular and Genetic Medicine, Department of Medicine and Regenerative Therapeutics, \\ Graduate School of Medicine; ${ }^{2}$ Division of Organ Pathology, Department of Pathology, Faculty of Medicine, \\ Tottori University; ${ }^{3}$ Division of General Thoracic Surgery, Tottori University Hospital, Yonago, Tottori 683-8504, Japan
}

Received March 6, 2016; Accepted January 12, 2017

DOI: $10.3892 / 01.2017 .5925$

\begin{abstract}
Non-small cell lung cancer (NSCLC) accounts for $>85 \%$ of incidences of lung cancer, for which the predicted 5 -year survival rates are low and recurrence rates remain high. Although it has been reported that the patients with SCLC cells that possess the cluster of differentiation (CD) 117 marker exhibited poor prognosis and poor response to chemotherapy, no studies concerning the association of CD117 expression with prognosis of the patients with NSCLC have been reported. An in vitro study reportedly revealed that CD117-positive cell populations in NSCLC cell lines exhibited cancer stem cell (CSC) phenotypes including self-renewal and chemoresistance. Therefore, the present study hypothesized that if CD117-positive cells are CSC-like cells, CD117 positivity may be associated with the prognosis of patients with NSCLC. To confirm this hypothesis, the association between CD117 expression in patients with NSCLC and clinicopathological characteristics was investigated. CD177 expression was examined by immunohistochemistry in 99 patients with NSCLC who underwent curative surgical resection. Tumor samples in the present study included 73 samples of adenocarcinoma and 26 of squamous carcinoma. The associations of CD177 expression with clinicopathological features and prognosis were examined. The lymph node metastasis and rates of recurrence were significantly associated with overall survival rates through multivariate analysis
\end{abstract}

Correspondence to: Dr Tomohiko Sakabe, Division of Organ Pathology, Department of Pathology, Faculty of Medicine, Tottori University, 86 Nishi-cho, Yonago, Tottori 683-8504, Japan

E-mail: saka0924@med.tottori-u.ac.jp

Abbreviations: NSCLC, non-small cell lung cancer; SCLC, small cell lung cancer; CSC, cancer stem cell; ADC, adenocarcinoma; SCC, squamous carcinoma; SCF, stem cell factor; GISTs, gastrointestinal stromal tumors; IgG, immunoglobulin G; K14, keratin 14

Key words: non-small cell lung cancer, immunohistochemistry, CD117, relapse-free survival, prognostic marker
$(\mathrm{P}<0.001$ and $\mathrm{P}<0.001)$, respectively. A Kaplan-Meier analysis for relapse-free survival and the log-rank test revealed that the patients with CD117-positive cell populations exhibited shorter relapse-free survival rates compared with patients whose cells were $\mathrm{CD} 117$-negative $(\mathrm{P}=0.014)$. The multivariate analysis demonstrated that venous invasion, pathological stage, and CD117 expression were independent prognostic parameters for relapse-free survival in patients with NSCLC $(\mathrm{P}=0.001, \mathrm{P}=0.001$ and $\mathrm{P}=0.002)$, respectively. In conclusion, these data suggest that CD117 expression in NSCLC may serve as a useful marker for predicting the prognosis of patients with NSCLC.

\section{Introduction}

The occurrence of cancer is increasing in association with the prevalence of established risk factors such as smoking, obesity and life style (1). In 2012, 14.1 million incident cancer cases and 8.2 million mortalities occurred worldwide (1). Lung cancer is the leading cause of cancer mortality in developed countries. In 2015, 221,200 incident cases of lung and bronchial cancer were estimated to be diagnosed and 158,040 mortalities were estimated to occur in the United States (2). Non-small cell lung cancer (NSCLC) is currently defined by pathological characteristics $(3,4)$. NSCLC represents $>85 \%$ incidences of lung cancer, for which the predicted 5-year survival rate is $15.9 \%$ and recurrence rates remain high at $30-50 \%$ (5). NSCLC is classified into two major histological phenotypes: Adenocarcinoma (ADC; $50 \%$ ) and squamous cell carcinoma (SCC; 40\%). ADCs generally arise in the distal airways, whereas SCCs arise in the proximal airways. Conversely, SCCs are more closely associated with cigarette smoking and chronic inflammation compared with ADCs $(3,4)$. A number of complex somatic alterations that extend beyond protein kinase activity to include transcription factors, epigenetic modifiers, and splicing variants were recently reported in NSCLCs (5-8). When somatic point mutations were analyzed using whole-exome sequence across 21 different tumor types, the mutation frequency in lung SCC and ADC ranked second and third highest, respectively (9). Additionally, heterogeneity of tumor microenvironments, such as tumor-associated macrophages and neutrophils, are associated with poor prognosis 
in NSCLC (10-12). Therefore, tumor heterogeneity provides explanation for poor responses to treatment of NSCLC.

The CD117 gene, termed c-Kit, encodes a tyrosine kinase growth factor receptor for stem cell factor (SCF), and has been extensively examined in hematopoietic stem cells (13). CD117 reportedly serves an important oncogenic role in solid tumors including gastrointestinal stromal tumors (GISTs) (14). Notably, it has been reported that CD117 expression was observed in small cell lung cancer (SCLC), and this molecule is associated with therapeutic and prognostic consequences in patients with SCLC $(15,16)$. Based on these findings, STI-571 (imatinib), which blocks the phosphorylation of the CD117 tyrosine kinase, has been developed and used for patients with GISTs. Additionally, it has been demonstrated that STI-571 demonstrates inhibitory effects on SCLC cell lines $(17,18)$. The overexpression of CD117 has been observed in NSCLC tumors $(19,20)$, suggesting that CD117 may be a therapeutic target in a subset of NSCLCs. In addition, CD117-positive NSCLC cells reportedly exhibit cancer stem cell (CSC) characteristics including self-renewal and chemoresistance (19). Previous experimental evidence suggests that the presence of CSCs may be associated with the prognosis of the patient in various types of tumor $(21,22)$. In the present study, it was hypothesized that if CD117 possesses prognostic significance in the patients with NSCLC, it may be used as a therapeutic target and prognostic marker for patients with NSCLC. To confirm this hypothesis, the association of CD117 expression with the clinicopathological characteristics of NSCLC was examined.

\section{Materials and methods}

Patients and clinical specimens. Formalin-fixed paraffin embedded tissue samples of NSCLC were obtained from 99 patients who were admitted to Tottori University Hospital (Yonago, Japan) between January 2005 and December 2007 and underwent curative surgical resection subsequent to informed consent. Detailed clinicopathological characteristics for these patients are summarized in Table I. The present study followed the principles of the Declaration of Helsinki and was approved by the ethics committees of Tottori University Faculty of Medicine (Yonago, Japan; approval no. 1830).

Immunohistochemical analysis. All specimens from 99 patients with NSCLC were fixed in $10 \%$ neutrally buffered formalin and embedded in paraffin. The fixed tissue sections of $3-\mu \mathrm{m}$ thickness were deparaffinized and treated with $3 \%$ hydrogen peroxide solution to block endogenous peroxidase activity. Subsequently, the sections were treated in sodium citrate buffer ( $\mathrm{pH}$ 6.0) using a 500-watt microwave oven for $12 \mathrm{~min}$ to improve the antigen retrieval. Subsequent to cooling to room temperature, the specimens were incubated for $1 \mathrm{~h}$ at $37^{\circ} \mathrm{C}$ with anti-CD117 monoclonal antibody (cat. no. ab32363; clone YR145; dilution, 1:250; Abcam, Cambridge, MA, USA). The sections were treated for $30 \mathrm{~min}$ at room temperature with biotinylated anti-rabbit immunoglobulin $\mathrm{G}$ (IgG) antibody (cat. no. BA-1000; dilution, 1:200; Vector Laboratories, Inc., Burlingame, CA, USA) and then incubated for $30 \mathrm{~min}$ at $37^{\circ} \mathrm{C}$ with streptavidin-biotinylated horseradish peroxidase complex (cat. no. SA-5004; dilution, 1:500;
Table I. Clinicopathological factors of patients with lung cancer.

\begin{tabular}{|c|c|}
\hline Characteristics & $\mathrm{n}$ \\
\hline No. of patients & 99 \\
\hline Age (year) & $69(26-81)$ \\
\hline \multicolumn{2}{|l|}{ Gender } \\
\hline Male/female & $59 / 40$ \\
\hline Maximum tumor size (mm) & $26(11-82)$ \\
\hline \multicolumn{2}{|l|}{ Lymph node metastasis } \\
\hline Negative/positive & $77 / 22$ \\
\hline \multicolumn{2}{|l|}{ Pleural invasion } \\
\hline Negative/positive & $73 / 26$ \\
\hline \multicolumn{2}{|l|}{ Lymphatic invasion } \\
\hline Negative/positive & $26 / 73$ \\
\hline \multicolumn{2}{|l|}{ Venous invasion } \\
\hline Negative/positive & $51 / 48$ \\
\hline \multicolumn{2}{|l|}{ Pathological stage } \\
\hline Stage I/Stage II/Stage III & $73 / 14 / 12$ \\
\hline \multicolumn{2}{|l|}{ Differentiation } \\
\hline Well/moderate/poor & $21 / 69 / 9$ \\
\hline \multicolumn{2}{|l|}{ Histological type } \\
\hline $\mathrm{Ad} / \mathrm{Sq}$ & $73 / 26$ \\
\hline \multicolumn{2}{|l|}{ Recurrence } \\
\hline Negative/positive & $85 / 14$ \\
\hline Overall survival (month) & $72(2-104)$ \\
\hline Relapse-free survival (month) & $66(2-104)$ \\
\hline
\end{tabular}

Ad, adenocarcinoma; Sq, squamous carcinoma. Values of age, maximum tumor size, overall survival, and relapse-free survival were provided as median and parenthetical values showed range.

Vector Laboratories, Inc.). Color development was achieved by the treatment with ImmPACT DAB Substrate (Vector Laboratories, Inc.) and counterstained with hematoxylin. Images were acquired using a Nikon Eclipse E800 upright microscope (Nikon Corporation, Tokyo, Japan). The results were evaluated by a pathologist who was blinded with respect to the clinicopathological characteristics. The stained samples were classified into the following two groups: The positive group, which was defined as the samples with the cell membrane expression of CD117; and the negative group, which was defined as the samples with no expression or cytoplasmic expression of CD117.

Statistical analysis. Microsoft Excel 2013 (Microsoft Corporation, Redmond, WA) and SPSS statics (version 22.0; SPSS, Inc., Chicago, IL, USA) were used for the statistical calculations. A $\chi^{2}$ test was performed to calculate the association between CD117 expression and the clinicopathological factors in patients with lung cancer. A univariable analysis using the log-rank test was performed to compare the overall survival ratio and disease free survival ratio in patients with lung cancer. A Cox regression model was used for the 
Table II. $\chi^{2}$ test of clinicopathological factors and CD117 expression.

\begin{tabular}{|c|c|c|c|}
\hline \multirow[b]{2}{*}{ Characteristics } & \multicolumn{2}{|c|}{ Sample size $(\%)$} & \multirow[b]{2}{*}{ P-value } \\
\hline & CD117- & CD117+ & \\
\hline Age (years) & & & 0.957 \\
\hline$\leq 69$ & $44(44.4)$ & $9(9.1)$ & \\
\hline$>69$ & $38(38.4)$ & $8(8.1)$ & \\
\hline Gender & & & 0.036 \\
\hline Male & $45(45.5)$ & $14(14.1)$ & \\
\hline Female & $37(37.4)$ & $3(3.0)$ & \\
\hline Maximum tumor size & & & 0.897 \\
\hline$\leq 26$ & $42(42.4)$ & $9(9.1)$ & \\
\hline$>26$ & $40(40.4)$ & $8(8.1)$ & \\
\hline Lymph node metastasis & & & 0.254 \\
\hline Negative & $62(62.6)$ & $15(15.2)$ & \\
\hline Positive & $20(20.2)$ & $2(2.0)$ & \\
\hline Pleural invasion & & & 0.746 \\
\hline Negative & $61(61.6)$ & $12(12.1)$ & \\
\hline Positive & $21(21.2)$ & $5(5.1)$ & \\
\hline Lymphatic invasion & & & 0.778 \\
\hline Negative & $22(22.2)$ & $4(4.0)$ & \\
\hline Positive & $60(60.6)$ & $13(13.1)$ & \\
\hline Venous invasion & & & 0.349 \\
\hline Negative & $44(44.4)$ & $7(7.1)$ & \\
\hline Positive & $38(38.4)$ & $10(10.1)$ & \\
\hline Pathological stage & & & 0.375 \\
\hline Stage I & $59(59.6)$ & $14(14.1)$ & \\
\hline Stage II/III & $23(23.2)$ & $3(3.0)$ & \\
\hline Histological type & & & 0.352 \\
\hline Ad & $62(62.6)$ & $11(11.1)$ & \\
\hline $\mathrm{Sq}$ & $20(20.2)$ & $6(6.1)$ & \\
\hline Differentiation & & & 0.693 \\
\hline Well & $18(18.2)$ & $3(3.0)$ & \\
\hline Moderately/poorly & $64(64.6)$ & $14(14.1)$ & \\
\hline Recurrence & & & $<0.001$ \\
\hline Absence & $75(75.8)$ & $10(10.1)$ & \\
\hline Presence & $7(7.1)$ & $7(7.1)$ & \\
\hline
\end{tabular}

Ad, adenocarcinoma; Sq, squamous carcinoma; CD, cluster of differentiation. Age and maximum tumor size were divided into two categories according to the median line.

multivariable analysis. $\mathrm{P}<0.05$ were considered to indicate a statistically significant difference.

\section{Results}

Clinicopathological features. The clinicopathological features of 99 patients enrolled in the present study are summarized in Table I. All patients were classified into two groups based on histology: ADC, 73 patients, and SCC,
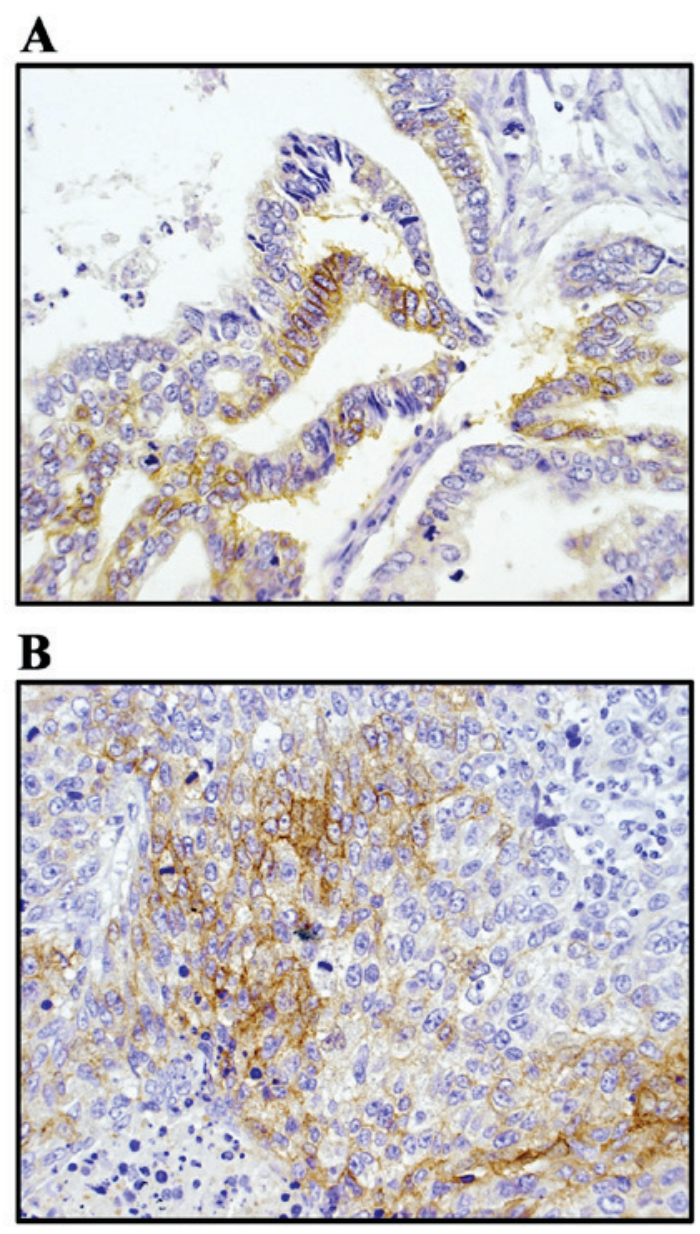

Figure 1. Immunohistochemical staining of CD117 expressions in patients with non-small cell lung cancer. Representative images of CD117 expression in FFPE non-small cell lung cancer tissues. Positive expression of CD117 in FFPE lung (A) adenocarcinoma tissues and FFPE lung (B) squamous cell carcinoma tissues. The expression of CD117 was demonstrated using the avidin-biotin complex staining method. All images were captured using a Nikon Eclipse E800 upright microscope (x400 magnification). FFPE, formalin-fixed paraffin-embedded; $\mathrm{CD}$, cluster of differentiation.

26 patients. Of those patients, 14 patients relapsed. The median overall survival and relapse-free survival were 72 (range 2-104) months and 66 (range 2-104) months in patients with ADC and SCC, respectively.

Expression ofCD117inNSCLCpatients.Immunohistochemical staining of CD117 expressions in 99 patients with NSCLC was performed. The representative images of CD117 expression in formalin-fixed paraffin-embedded sections are demonstrated in Fig. 1. Positive expression of CD117 in lung ADC and SCC tissues are illustrated in Fig. 1A and B, respectively. CD117 was expressed mainly on the cell membrane and occasionally in the cytoplasm of cancer cells.

Association of CD117 expression with clinicopathological features. The CD117 protein expression was positive in 17 cases, whereas it was negative in 82 cases, as summarized in Table II. The result from clinicopathological analysis revealed that CD117 positivity is significantly associated with gender and recurrence rate. The positivity of CD117 expression was higher in males compared with females $(\mathrm{P}<0.05)$ and was 
Table III. Univariate and multivariate analysis of clinical variables associated with overall survival in patients with lung cancer.

\begin{tabular}{llrr}
\hline & & Univariate & Multivariate univariate \\
\cline { 3 - 4 } Characteristics & \multicolumn{1}{c}{ Category } & P-value & HR (95\% CI) \\
\hline Age & $\leq 69$ vs. $>69$ & 0.172 & \\
Gender & Male vs. Female & 0.596 & \\
Maximum tumor size & $\leq 26$ vs. $>26$ & 0.003 & $<.055(2.004-8.205)$ \\
Lymph node metastasis & Negative vs. Positive & $<0.001$ & $<0.001$ \\
Pleural invasion & Negative vs. Positive & 0.015 & \\
Venous invasion & Negative vs. Positive & $<0.001$ & \\
Pathological stage & Stage I vs. Stage II/III & 0.005 & \\
Differentiation & Well vs. Moderate/Poor & $<0.001$ & \\
Recurrence & Negative vs. Positive & 0.113 & \\
CD117 expression & Negative vs. Positive & $4.672(2.264-9.638)$ \\
\hline
\end{tabular}

HR, hazard ratio; $\mathrm{CI}$, confidence interval; $\mathrm{CD}$, cluster of differentiation.

Table IV. Univariate and multivariate analysis of clinical variables associated with relapse-free survival in patients with lung cancer.

\begin{tabular}{|c|c|c|c|c|}
\hline \multirow[b]{2}{*}{ Characteristics } & \multirow[b]{2}{*}{ Category } & \multirow{2}{*}{$\frac{\text { Univariate }}{\text { P-value }}$} & \multicolumn{2}{|c|}{ Multivariate univariate } \\
\hline & & & HR (95\% CI) & $\mathrm{P}$-value \\
\hline Age & $\leq 69$ vs. $>69$ & 0.213 & & \\
\hline Gender & Male vs. Female & 0.458 & & \\
\hline Maximum tumor size & $\leq 26$ vs. $>26$ & $<0.001$ & & \\
\hline Lymph node metastasis & Negative vs. Positive & $<0.001$ & & \\
\hline Pleural invasion & Negative vs. Positive & 0.002 & & \\
\hline Venous invasion & Negative vs. Positive & $<0.001$ & $4.596(2.053-10.289)$ & $<0.001$ \\
\hline Pathological stage & Stage I vs. Stage II/III & $<0.001$ & $3.347(1.685-6.651)$ & 0.001 \\
\hline Differentiation & Well vs. Moderate/Poor & $<0.001$ & & \\
\hline CD117 expression & Negative vs. Positive & 0.014 & $3.352(1.583-7.096)$ & 0.002 \\
\hline
\end{tabular}

HR, hazard ratio; $\mathrm{CI}$, confidence interval; $\mathrm{CD}$, cluster of differentiation.

also higher in recurrent patients compared with non-recurrent patients $(\mathrm{P}<0.001)$. Notably, $50 \%$ of recurrent patients exhibited CD117 positivity. Meanwhile, CD117 positivity was not associated with age, tumor size, pleural effusion, venous invasion, pathological stage, histological type or differentiation.

Prognostic significance of CD117 expression in NSCLC patients. To investigate the association between clinicopathological variables, including CD117 expression, and prognosis of patients with NSCLC, a Kaplan-Meier analysis was performed. As demonstrated in Table III, the univariate analysis identified that overall survival was associated with maximum tumor size $(\mathrm{P}=0.003)$, lymph node metastasis $(\mathrm{P}<0.001)$, pleural effusion $(\mathrm{P}=0.015)$, venous invasion $(\mathrm{P}=0.001)$, pathological stage $(\mathrm{P}<0.001)$, differentiation $(\mathrm{P}=0.005)$ and recurrence $(\mathrm{P}<0.001)$. However, overall survival was not associated with age, gender or CD117 expression. Additionally, the multivariate analysis showed that only lymph node metastasis and recurrence were significantly associated with overall survival $(\mathrm{P}<0.001$, each), as illustrated in Table III. When patients were classified into CD117-negative and CD117-positive groups, the Kaplan-Meier analysis for overall survival demonstrated that patients with CD117-positive cell populations tended to exhibit shorter overall survival rates compared with patients with CD117-negative cell populations ( $\mathrm{P}=0.113$; Fig. 2). Additionally, the Kaplan-Meier analysis for relapse-free survival was performed according to the expression of CD117 and revealed that patients with CD117-positive cell populations exhibited significantly shorter survival rates compared with patients with CD117-negative cell populations $(\mathrm{P}=0.014$; Fig. 3$)$. In addition to $\mathrm{CD} 117$ expression, the following clinicopathological variables were associated with relapse-free survival: Maximum tumor size $(\mathrm{P}<0.001)$, lymph node metastasis $(\mathrm{P}<0.001)$, pleural effusion $(\mathrm{P}=0.002)$, venous invasion $(\mathrm{P}<0.001)$, pathological stage 


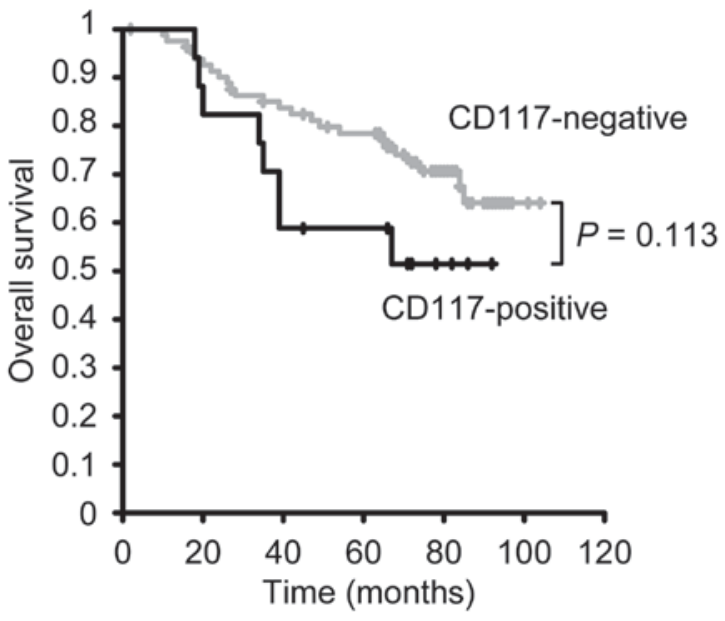

Figure 2. Kaplan-Meier analysis for overall survival rate in 99 non-small lung cancer cell patients. Patients were classified into negative (82 cases) and positive groups (17 cases) according to the expression of CD117. Data analysis was performed using the log-rank test. $\mathrm{CD}$, cluster of differentiation, gray curve, CD117-negative group; black curve, CD117-positive group.

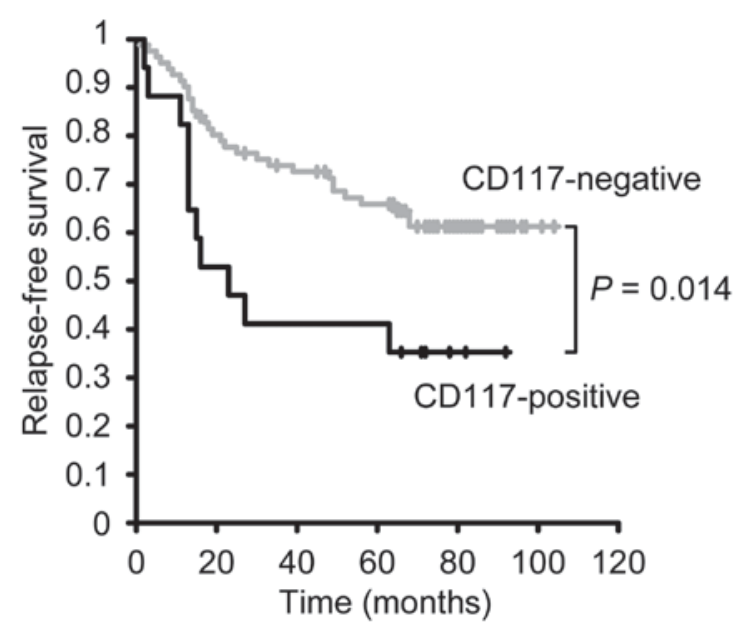

Figure 3. Kaplan-Meier analysis for relapse-free survival in 99 non-small lung cancer cell patients. Patients were classified into negative ( 82 cases) and positive groups (17 cases) according to the expression of CD117. Data analysis was performed using the log-rank test. $\mathrm{CD}$, cluster of differentiation, gray curve, CD117-negative group; black curve, CD117-positive group.

$(\mathrm{P}<0.001)$ and differentiation $(\mathrm{P}<0.001)$, as summarized in Table IV. The multivariable analysis revealed that relapse-free survival was significantly associated with venous invasion $(\mathrm{P}<0.001)$, pathological stage $(\mathrm{P}=0.001)$ and $\mathrm{CD} 117$ expression $(\mathrm{P}=0.002)$. These findings suggest that $\mathrm{CD} 117$ expression is an independent factor for predicting relapse-free survival and may serve as a prognostic marker for tumor recurrence and survival in patients with NSCLC.

\section{Discussion}

In the present study, the patients with CD117-positive expression in NSCLC tissues exhibited significantly shorter relapse-free survival compared with patients with CD117-negative expression. This is the first report that CD117 expression may be a predictive marker for poor prognosis in the patients with NSCLC. CD117 expression in a subset of patients with NSCLC was not predictive of overall survival (20), which is in agreement with the present study due to the small number of patients enrolled. However, the present study demonstrates that CD117 expression is associated with the relapse-free survival. Additionally, the combined treatment of cisplatin with imatinib or anti-SCF antibody reportedly inhibits the growth of NSCLC cells (19). These findings are similar to the reports that $\mathrm{CD} 117$ expression is associated with poor prognosis in SCLC $(15,16)$. Taken together, these data suggest that the SCF/CD117 axis is a therapeutic target of a subset of lung cancer cells, and the inhibition of this signaling pathway may improve the efficacy of chemotherapy in lung cancer.

The majority of solid tumors are composed of a heterogeneous population including cells characterized by capacity for differentiation, self-renewal and resistance to chemotherapy, and radiotherapy $(23,24)$. Although $\sim 20 \%$ of patients with NSCLC exhibited surgically-correctable tumors at presentation, the recurrence rates following surgery remain high at $30-50 \%$ (25). This indicates that there is minimal residual disease, which contains a population that possesses a high proliferative potential and self-renewal capacity. To delay or prevent tumor recurrence in lung cancer, there should be a focus on the stem-like cells present. Some CSC markers have been identified in lung cancer, including a subset of keratin 14-expressing progenitor epithelial cells, which are involved in airway epithelial repair subsequent to injury, were reported to be tumor-initiating cells in the subgroup of smokers with NSCLC (26). Additionally, CD133-positive lung cancer cells exhibited CSC-like features, such as increased tumorigenic potential and higher sphere-forming ability $(27,28)$. CD133 expression in NSCLC represents an anticancer drug resistance phenotype and evidence of metastatic cells, but does not correlate with the survival of patients with NSCLC (29). Conversely, another study suggests that $\mathrm{CD} 133$ expression is a temporary marker of CSCs in SCLC but not in NSCLC (30). CSC populations isolated from NSCLC cell lines were reported to express SCF and CD117 in an autocrine fashion (19). Although cisplatin treatment did not eliminate CSCs from NSCLC cells, inhibition of the SCF-CD117 axis by imatinib or anti-SCF antibody suppressed CSC proliferation (19), which suggests that this signaling pathway serves an important role in lung CSCs maintenance and survival. In the present study, CD117-positivity was associated with relapse-free survival, but not with overall survival, suggesting that CD117-positive cells may exhibit some CSC characteristics. Additional research is required to demonstrate that the acquisition of cancer stemness in NSCLC cells is associated with poor prognosis in patients with NSCLC.

In conclusion, the present study demonstrated that the positive expression of CD117 is significantly associated with a shorter relapse-free survival rate in patients with NSCLC. This observation suggests that CD117 may serve as a prognostic marker for predicting poor prognoses and a novel therapeutic target for patients with NSCLC.

\section{Acknowledgements}

The present study was supported by Management Expenses Grants from Ministry of Education, Culture, Sports, Science and Technology in Japan. 


\section{References}

1. Torre LA, Bray F, Siegel RL, Ferlay J, Lortet-Tieulent J and Jemal A: Global cancer statistics, 2012. CA Cancer J Clin 65: 87-108, 2015

2. Ettinger DS, Wood DE, Akerley W, Bazhenova LA, Borghaei H, Camidge DR, Cheney RT, Chirieac LR, D'Amico TA, Demmy TL, et al: Non-small cell lung cancer, version 6.2015 . J Natl Compr Canc Netw 13: 515-524, 2015.

3. Langer CJ, Besse B, Gualberto A, Brambilla E and Soria JC: The evolving role of histology in the management of advanced non-small-cell lung cancer. J Clin Oncol 28: 5311-5320, 2010.

4. Davidson MR, Gazdar AF and Clarke BE: The pivotal role of pathology in the management of lung cancer. J Thorac Dis 5 (Suppl 5): S463-S478, 2013.

5. Chen Z, Fillmore CM, Hammerman PS, Kim CF and Wong KK: Non-small-cell lung cancers: A heterogeneous set of diseases. Nat Rev Cancer 14: 535-546, 2014.

6. Cancer Genome Atlas Research Network. Comprehensive genomic characterization of squamous cell lung cancers. Nature 489: 519-525, 2012.

7. Kandoth C, McLellan MD, Vandin F, Ye K, Niu B, Lu C, Xie M, Zhang Q, McMichael JF, Wyczalkowski MA, et al: Mutational landscape and significance across 12 major cancer types. Nature 502: 333-339, 2013.

8. Cancer Genome Atlas Research Network. Comprehensive molecular profiling of lung adenocarcinoma. Nature 511: 543-550, 2014

9. Lawrence MS, Stojanov P, Mermel CH, Robinson JT, Garraway LA, Golub TR, Meyerson M, Gabriel SB, Lander ES and Getz G: Discovery and saturation analysis of cancer genes across 21 tumour types. Nature 505: 495-501, 2014.

10. Bellocq A, Antoine M, Flahault A, Philippe C, Crestani B, Bernaudin JF, Mayaud C, Milleron B, Baud L and Cadranel J: Neutrophil alveolitis in bronchioloalveolar carcinoma: Induction by tumor-derived interleukin- 8 and relation to clinical outcome. Am J Pathol 152: 83-92, 1998.

11. Murdoch C, Muthana M, Coffelt SB and Lewis CE: The role of myeloid cells in the promotion of tumour angiogenesis. Nat Rev Cancer 8: 618-631, 2008.

12. Houghton AM, Rzymkiewicz DM, Ji H, Gregory AD, Egea EE, Metz HE, Stolz DB, Land SR, Marconcini LA, Kliment CR, et al: Neutrophil elastase-mediated degradation of IRS-1 accelerates lung tumor growth. Nat Med 16: 219-223, 2010.

13. Yarden Y, Kuang WJ, Yang-Feng T, Coussens L, Munemitsu S, Dull TJ, Chen E, Schlessinger J, Francke U and Ullrich A: Human proto-oncogene c-kit: A new cell surface receptor tyrosine kinase for an unidentified ligand. EMBO J 6: 3341-3351, 1987.

14. Hirota S: Gastrointestinal stromal tumors: Their origin and cause. Int J Clin Oncol 6: 1-5, 2001.

15. Naeem M, Dahiya M, Clark JI, Creech SD and Alkan S: Analysis of c-kit protein expression in small-cell lung carcinoma and its implication for prognosis. Hum Pathol 33: 1182-1187, 2002.

16. Micke P, Basrai M, Faldum A, Bittinger F, Rönnstrand L, Blaukat A, Beeh KM, Oesch F, Fischer B, Buhl R and Hengstler JG: Characterization of c-kit expression in small cell lung cancer: Prognostic and therapeutic implications. Clin Cancer Res 9: 188-194, 2003.
17. Krystal GW, Honsawek S, Litz J and Buchdunger E: The selective tyrosine kinase inhibitor STI571 inhibits small cell lung cancer growth. Clin Cancer Res 6: 3319-3326, 2000.

18. Wang WL, Healy ME, Sattler M, Verma S, Lin J, Maulik G, Stiles CD, Griffin JD, Johnson BE and Salgia R: Growth inhibition and modulation of kinase pathways of small cell lung cancer cell lines by the novel tyrosine kinase inhibitor STI 571. Oncogene 19: 3521-3528, 2000

19. Levina V, Marrangoni A, Wang T, Parikh S, Su Y, Herberman R, Lokshin A and Gorelik E: Elimination of human lung cancer stem cells through targeting of the stem cell factor-c-kit autocrine signaling loop. Cancer Res 70: 338-346, 2010.

20. Donnenberg AD, Zimmerlin L, Landreneau RJ, Luketich JD and Donnenberg VS: KIT (CD117) expression in a subset of non-small cell lung carcinoma (NSCLC) patients. PloS One 7: e52885, 2012.

21. Yang F, Cao L, Sun Z, Jin J, Fang H, Zhang W and Guan X: Evaluation of breast cancer stem cells and intratumor stemness heterogeneity in triple-negative breast cancer as prognostic factors. Int J Biol Sci 12: 1568-1577, 2016.

22. Song W, Li H, Tao K, Li R, Song Z, Zhao Q, Zhang F and Dou K: Expression and clinical significance of the stem cell marker CD133 in hepatocellular carcinoma. Int J Clin Pract 62: 1212-1218, 2008

23. Hassan HT: c-Kit expression in human normal and malignant stem cells prognostic and therapeutic implications. Leuk Res 33: $5-10,2009$.

24. Alamgeer M, Peacock CD, Matsui W, Ganju V and Watkins DN: Cancer stem cells in lung cancer: Evidence and controversies. Respirology 18: 757-764, 2013.

25. Kelsey CR, Marks LB, Hollis D, Hubbs JL, Ready NE, D'Amico TA and Boyd JA: Local recurrence after surgery for early stage lung cancer: An 11-year experience with 975 patients. Cancer 115: 5218-5227, 2009.

26. Ooi AT, Mah V, Nickerson DW, Gilbert JL, Ha VL, Hegab AE, Horvath S, Alavi M, Maresh EL, Chia D, et al: Presence of a putative tumor-initiating progenitor cell population predicts poor prognosis in smokers with non-small cell lung cancer. Cancer Res 70: 6639-6648, 2010.

27. Bertolini G, Roz L, Perego P, Tortoreto M, Fontanella E, Gatti L, Pratesi G, Fabbri A, Andriani F, Tinelli S, et al: Highly tumorigenic lung cancer CD133+ cells display stem-like features and are spared by cisplatin treatment. Proc Natl Acad Sci USA 106: 16281-16286, 2009.

28. Eramo A, Lotti F, Sette G, Pilozzi E, Biffoni M, Di Virgilio A, Conticello C, Ruco L, Peschle C and De Maria R: Identification and expansion of the tumorigenic lung cancer stem cell population. Cell Death Differ 15: 504-514, 2008.

29. Salnikov AV, Gladkich J, Moldenhauer G, Volm M, Mattern J and Herr I: CD133 is indicative for a resistance phenotype but does not represent a prognostic marker for survival of non-small cell lung cancer patients. Int J Cancer 126: 950-958, 2010.

30. Cui F, Wang J, Chen D and Chen YJ: CD133 is a temporary marker of cancer stem cells in small cell lung cancer, but not in non-small cell lung cancer. Oncol Rep 25: 701-708, 2011. 